\title{
Green Building Materials Research on Climate Change
}

\author{
Nan Lin \\ School of Civil Engineering and Architecture, Wuhan Polytechnic University, Wuhan, China \\ 430023 \\ 4304835@qq.com
}

\begin{abstract}
Keywords: Climate Change, Green Building, Building Materials, Low Carbon Environmental Protection, Energy Saving
\end{abstract}

\begin{abstract}
This article introduced under the challenge of global climate change, advocating the importance of green building materials application. Green building is the one of the most effective way to energy conservation and emissions reduction. Analyzed the climate change on building engineering, construction environment, construction materials, affecting the performance of the relationship between green architecture and regional climate as well as the problems that should be paid attention to in the design. From building materials manufacturing technology research, the improvement of life and durability, low carbon emissions of gelled material several aspects discusses the development of green building materials, and summarized the application of environmental protection and energy saving materials, prospects the future development.
\end{abstract}

\section{Introduction}

With remarkable climate summit in Paris in 2016, the environment and climate change has become one of the important topics of the world concern, protect the environment and solve the problem of climate change become the common challenges facing the world, is also the only way to achieve sustainable development. China will peak around 2030 carbon dioxide emissions, and strive to achieve as soon as possible. Unit of gross domestic product in 2030 carbon dioxide emissions $60 \%$ to $66 \%$ lower than in 2005 , non-fossil energy of primary energy consumption to around $20 \%$, forest volume of more than 4.5 billion cubic meters in 2005[1]. Start in the developing countries 10 low carbon demonstration area, 100 slow and adapt to climate change project, continue to promote clean energy, disaster prevention and mitigation, ecological protection, low carbon smart international cooperation in the field of urban construction, etc.

\section{The Meaning of Advocating Green Building}

In the process of social and economic development, advocacy of "green, environmental protection, energy saving" of production and life style, is to improve the environment and the important measure to solve the problem of climate change. In the face of the challenge of global climate change, green building is one of the most important areas. Energy consumption of the three major parts, respectively is industrial, transportation and construction. The calculation of the European Union standards show that the whole construction process of global resources and the environment, the influence of resource consumption, energy was $50 \%$, water $42 \%$, raw material was $50 \%$, the arable land is $48 \%$; Pollution: air pollution for $50 \%$, greenhouse gas emissions $42 \%$, water pollution was $50 \%$, the solid waste was $48 \%$, the fluorine chlorine was $50 \%$ [2].

You can see that the whole construction process consumes a lot of resources and energy, to produce the same amount of pollution and emissions. Therefore, building energy conservation will be one of the main strategy to respond to climate change. Green building because of its energy-saving and land-saving, water saving, material saving, environmental protection features, become the one of the most effective way to energy conservation and emissions reduction. 


\section{The Influence of Climate Change on the Construction of Environment}

The main reason of climate change is caused by human activities increased concentrations of greenhouse gases in the atmosphere. Greenhouse gas emissions from the national economy in various sectors, the energy consumption in the construction industry is one of the main sources of greenhouse gases. Developed countries use energy consumption accounts for about $30 \%$ to $40 \%$ of total energy consumption. Building energy consumption accounts for the proportion of the total energy consumption is larger, the more its greenhouse gas emissions.

Climate Change Directly Affects the Safety of Construction Projects, Applicability and Durability. Climate change will cause the increase of the frequency and intensity of torrential rain, causing floods destroyed buildings, causing enormous losses, and it caused great threat on the safety of construction projects. The increase of wind speed will lead to different degree of damage. Due to rising temperatures or hot decreased soil moisture content, influence and harm to buildings foundation. Temperature and humidity changes, the increase of the concentration of carbon dioxide in the atmosphere, will speed up the carbonization of concrete, affect the durability of building engineering.

Construction engineering general relatively long service life, most of the existing buildings in the next few decades will continue to use, this will inevitably be a direct impact on all aspects of climate change. Therefore, in order to decrease the loss of the future, it is necessary to take effective measures, make construction to adapt to climate change in the future.

Construction Environment Impact of Climate Change. Construction of the building environment involves different construction materials, construction technology, construction site management, etc., and climate change make existing construction material and technology are showing a certain inadaptability, but also caused some impact on the use of equipment environment. In addition, using a large amount of concrete in building engineering construction materials, climate change will inevitably lead to concrete structure stress affected, more prone to fracture.

\section{The Influence of Climate Change on Building Materials}

Temperature Affect the Properties of Concrete Material. The temperature changes concrete material properties such as strength, deformation. Usually temperature results in the decrease of concrete material strength, elastic modulus, deformation increase. For concrete material, temperature on the two opposite effects: on the one hand, the temperature rise accelerate the hydration reaction rate, promote the development of the early strength of concrete; On the other hand, the temperature lead to evaporation speed, can use water to reduce in the hydration. Therefore, the high temperature hot climate and delayed the spray reaction process. It is generally believed that high temperature can have an adverse effect on the later strength of concrete.

Humidity Affect the Performance of Concrete Material. Climate change will lead to the change of environmental humidity, resulting in the change of moisture content inside the concrete, affecting its mechanical performance. The increase of moisture content reduced the compressive strength of concrete.

Other Climate Factors Influence on Building Materials. Climate change leads to the increase of UV will speed up the degradation of polymer materials in construction speed, thereby reducing the service life of materials. Plastic, metal, stone, glass, wood, brick and tile building materials will be affected by the influence and destruction of climate factors such as rain, high temperature and strong sunshine, carbon dioxide levels increase.

\section{Green Building and Regional Climate}

Architecture is one of the major sources of greenhouse gas emissions, has an important influence on climate change. Green building meets with low energy consumption, low emissions of greenhouse gases to the characteristics of the low carbon era requirement, suit the theme of energy conservation and emissions reduction response to global climate change. Green building is closely related to the 
regional climate, economic conditions. Climate environment, economic development differences from region to region, the current green building standards system is not fully considering the regional differences, regional differentiation standards to be formulated. Therefore, requires a combination of all resources, climate, economic and cultural characteristics to establish high pertinence, feasibility of green building standards system and the detailed rules for the implementation. In the design, according to the principle of natural ventilation air cooling system, make the building can effectively use the dominant wind direction in summer. Building adopts flat form suitable for the local climate conditions and the overall layout.

\section{Research Development of Green Building Materials}

Building Materials Manufacturing Energy-Saving Technology Research. In the field of building materials, carbon dioxide emissions including direct emissions and the indirect emissions. Direct emissions from fossil fuel combustion and decomposition of limestone and indirect emissions from electricity consumption. The cement industry has great influence to the climate change. Building materials manufacturing and application fields, therefore, still with high efficiency and energy saving, save resources processing and manufacturing technology and prolonging the service life of products for the overall development goals. In cement, for example, its energy saving manufacturing includes the following aspects (refer with: Table 1) [3].

Table 1. The Energy Saving Manufacturing of Cement

\begin{tabular}{|c|l|}
\hline Development Direction & \multicolumn{1}{c|}{ Technical Research } \\
\hline \multirow{4}{*}{ Replace the Fuel } & With low fossil fuel alternatives to traditional fuels \\
\cline { 2 - 2 } & Use calcium carbonate raw material instead of limestone \\
\cline { 2 - 2 } & Replace cement clinker using industrial waste residue \\
\cline { 2 - 2 } $\begin{array}{c}\text { Energy Saving Processing } \\
\text { Manufacturing }\end{array}$ & $\begin{array}{l}\text { Use combustible waste materials such as waste tires, } \\
\text { waste oil, as alternative fuels }\end{array}$ \\
\cline { 2 - 2 } \begin{tabular}{l} 
Efficient precalcining kiln technology \\
\cline { 2 - 2 } $\begin{array}{c}\text { Adjust the Material } \\
\text { Composition }\end{array}$
\end{tabular} & $\begin{array}{l}\text { Efficient heat preservation and long-life refractory } \\
\text { materials }\end{array}$ \\
\cline { 2 - 2 } & $\begin{array}{l}\text { Low energy consumption of cement, reduce carbon } \\
\text { dioxide emissions }\end{array}$ \\
\hline
\end{tabular}

Foreign energy saving technology research mainly include: around the glass melting process in technology research, reduce energy consumption and pollutant emissions in the process of glass making; Around the glass clarification process technology research, decrease the temperature of glass clarification, so as to achieve energy-saving purpose; Around the glass factory waste gas waste heat utilization technology research, the maximum energy recycling waste away.

Extend the Life of the Building Materials and Increase Durability. Application of modern science and technology, by studying the mechanism of the durability of materials and the innovation of the test method, the research material composition, structure and the change rule between durability, solve the technical problems of long life, high durability. For example, in the aspect of improving the durability of cement base material, the multi-factor synergism the failure process and failure mechanism of concrete, and in evaluating the service life of concrete based on concrete durability design.

The Research and Development of Low Carbon Gelled Material. Can be casting, high durability, high strength gypsum is currently building materials research hot spot and direction. Cement production needs to consume large amounts of lime raw materials and energy, cement concrete as a building material is difficult to recycle after abandoned. While casting, high durability, 
high strength gypsum production, basic not emit carbon dioxide, after simple processing waste gypsum wall materials can be reused [4].

Many industrial waste residue through appropriate combination can occur at high pressure polymerization, get very high strength can be used in the production of wall materials and other building materials products, can effectively reduce the dosage of the cement.

\section{The Application of Environmental Protection and Energy Saving Building Materials}

Foam concrete block. It is a kind of aerated concrete block, its appearance quality, internal porosity structure, performance and autoclaved aerated concrete block are basically the same. This is a new type of energy conservation and environmental protection wall materials, with light weight, high strength, reduce building load; Good pressure resistance; Good vibration resistance; No crack, long service life; Water resistance good outstanding characteristic.

New thermal insulation material. In the heat loss of the building palisade structure of $70 \%-80 \%$, therefore, to strengthen the palisade structure heat preservation and heat insulation performance is very important. At present, the thermal insulation material on the application of different degrees of defects: calcium silicate in damp environment easy corrosion; Glass fiber and mineral cotton easily absorb moisture, the loss of heat preservation performance; Foam plastics are not resistant to high temperature [5]. In order to overcome the shortcoming, a lightweight multifunctional composite insulation materials, mainly used in walls and roofing system.

\section{Conclusions}

Green building materials is not only within the industry waste water, waste gas, waste heat, waste residue use, what is more important to coal, steel, electricity and chemical industries such as ecological link and effective utilization of industrial waste residue replace natural resources. The research and application of new materials, energy saving to promote green building materials, muti function change, standardization, high energy consumption construction to develop low energy consumption, zero energy consumption, effectively cope with climate change.

\section{Acknowledgement}

This work was financially supported by the Science and Technology Research Project "Green Building Development Strategy Research on Climate Change" of Department of Housing and Urban-Rural Development of Hubei Province.

\section{References}

[1] Gu Zhenan, Yao Yan, Yan Bilan, Development of Green Building Materials Cope with the Challenge of Climate Change, Advanced Materials Industry[J]. 2010 (3) 49-53.

[2]Deng Minzhen, To Promote Green Buildings in China: Lessons from the USA and EU, J. Resour. Ecol. Macmillan[J]. 2012 (2) 183-191.

[3] Zhang Mingshun, Wu Chuan, Zhang Xiaozhuan, Zhao Siqi, Handbook Green Building Development, Chemical Industry Press, China, 2014.

[4] Shanghai Building Energy Conservation and Green Building Policy and Development Report (2013), Shanghai Building Materials[J].2014 (4) 1-5.

[5] (7 Group) Bill Reed, The Integrative Design Guide to Green Building: Redefining the Practice of Sustainalility . China building industry press, 2016. 